\title{
Digital Mariner's Routeing Guide - An Exploration of the Standardization and Online Delivery of Marine Information
}

\author{
Raphael M MALYANKAR, USA \\ Jeppesen \\ Topic: Poster; $(D, E)$

\section{INTRODUCTION}

Maritime data is produced in a variety of forms. This poster describes a prototype application intended to demonstrate the harmonisation of vector data with textual information, produced by different sources, and deliver it to end-users in an integrated and user-friendly form.

The chosen vehicle for this is a prototype online mariner's routeing guide using a data model based on the International Hydrographic Organisation (IHO) S-100 standard and developed using web services to make the information available to end users over the World-Wide Web. The producers of the content information are the Hydrographic Offices of three North Sea nations and the end users are mariners. Mariners' routeing guides are used for voyage planning. Current solutions are paper and PDF routeing guides, though a few digital versions have recently been developed. The IHO has produced a standards for (paper) routeing guides [International Hydrographic Organisation, 2010a].

The project uses the new IHO S-100 standard [International Hydrographic Organisation, 2010b] and product specifications based on it. Providing better information to mariners and making it easily accessible facilitates more efficient routeing of vessels, avoidance of dangers, avoidance of environmentally sensitive areas, and helps mariners become aware of rules pertaining to environmentally sensitive areas, reducing negative impacts of shipping on the envoronment.

\section{OVERVIEW}

Mariner's routeing guides are a mixture of textual, graphic, and geographic information about traffic separation, recommended routes, ship reporting systems, regulations for navigation and environmental protection, and other information. They provide an overview of the information needed by navigation officers for planning voyages. Their presentation to end-users combines different types of information, including geographic features from nautical charts and text extracts from publications, in a largely graphical product.

The prototype Digital Mariner's Routing Guide (DMRG) described in this paper is a web-based system demonstration that will allow mariners to view information from different North Sea ports that has been converted to the new IHO S-100 data framework. DMRG features include:

- a user-controlled graphical display of land and sea areas, traffic separation, ship reporting, restricted areas, nature preserves, and similar information of use in voyage planning;

- auxiliary displays of specific information on navigation, rules and regulations, environmental protection, and other topics;

- different types of information access functionality, including geographic searches, intended to provide users with efficient access to information.

Data for the DMRG consists of geographic features from ENCs and extracts from text official nautical publications of hydrographic offices and other sources, converted to a format compatible with both S100 and GML (Geography Markup Language). The current implementation is concerned with selected ports in Norway, Denmark, and Germany, and was executed with the participation of the Norwegian Hydrographic Service (NHS), Bundesamt für Seeschifffahrt und Hydrographie (BSH), and Kort \& Matrikelstyrelsen (KMS) in converting data from their publications to the new information model. 


\section{STANDARDS-BASED INFORMATION}

The IHO has recently developed a framework standard for nautical publications, based on the ISO 19100 family of standards. The S-100 standard [International Hydrographic Organisation, 2010b] is a framework from which standards for different data types and data products are derived. Examples of such derived standards are the S-101 and S-102 Product Specifications, both currently under development, which describe data models for ENC and high-density bathymetry data respectively. The IHO Standardisation of Nautical Publications Working Group (SNPWG) is working on a data model for nautical publications based on S-100. The scope of this model is far larger than digital mariners routing guides - it is a general model intended for making nautical publications information compatible with future Electronic Chart Display and Information System (ECDIS). At the core of the S100 model are the concepts of geographic features (representations of real world phenomena) and information types (identifiable, discrete units of information which may be shared among features). The geographic objects in this model range from radio stations to port security areas. The information objects range from regulations to address/contact information, ship reports, hours of work, and specification of classes of vessels to which a rule applies. The SNPWG model is still evolving, but the DMRG work used the then-current version of the SNPWG model as its own data model.

The S-100 standard allows for different formats for data sets. The encoding for this product specification was defined using an XML application schema derived from GML 3.2.1. The encoding is capable of coding geographic features, information objects, simple and complex attributes, feature associations, information associations.

\section{INFORMATION CONTENT}

Mariners' Routeing Guides serve the purpose of bringing together several critical types of information needed for the task of creating a route plan for a voyage. Historically these have been produced in the form of a paper chart, but now there are examples of digital mariners' routeing guides. Today's examples, digital and paper, provide a basis for developing more intelligent presentations of data and facilitating trans-national harmonisation of nautical information.

\section{Source Material}

The selection of source material was guided by the eventual application, namely the digital routeing guide. Source material consisted mainly of Sailing Directions or the equivalent, and electronic nautical charts (ENC) files. The ENC files were used mainly to determine the geographic locations with which information from the publications is associated.

The structure and volume of the source texts varied widely in their descriptions of the port areas and approaches. The Norwegian sailing directions for the Stavanger area (in Den Norske Los, Volume 3) are written as plain text in a narrative style, include several lists (of landmarks, pilot boarding places, etc.) and describe the approaches from seaward as well as providing details about berth sizes and port services. KMS has replaced printed sailing directions for port areas with web pages for individual ports, available on the KMS web site as Danske Havnelods. The structure is less of a flowed narrative compared to Den Norske Los, and is distinguished from the other two in using pictograms to convey some of its information about port services. BSH provides the equivalent information in Part C of the Nordsee Handbuch. This is structured as short sentences and sentence fragments which contain the essential information, and makes intensive use of visual style cues such as fonts and indentation to arrange associated information elements together and indicate the areas and vessels to which specific rules apply. Den Norske Los tends to provide area-specific regulations in full, compared to the other two; the Nordsee Handbuch presents them as text fragments prescribing or forbidding actions, under heads indicating the conditions under which a the specific prescription/prohibition applies. All three arrange the information under similar heads and subheads. All three hydrographic offices provide general information and the text of regulations in volumes or chapters different from the area-specific 
information - Volume 1 of Den Norske Los for Norway, a printed publication called Den Danske Lods for Denmark (not currently available on the Web), and Part A of the Nordsee Handbuch for Germany. The presentation of this information is more consistent across the three countries.

\section{Preparation of Information}

As part of the project Jeppesen, $\mathrm{BSH}, \mathrm{KMS}$, and NHS converted unstructured textual information from nautical publications for one port each from Denmark, Germany, and Norway into structured data conforming to the IHO SNPWG data model and produced XML datasets for the three ports. The information mapping work for this project was performed by project participants at $\mathrm{BSH}, \mathrm{NHS}$, and KMS, and reviewed by Jeppesen. Coordinates for geographic features were determined from the text if available; if not, the coordinates were obtained from the appropriate ENC or created in an ENC editing tool.

Hydrographic office partners reported that information mapping took significant effort. A large fraction of the time was spent on linkages to geometry, in the form of geographic features or spatial objects. Also, preparing extracts of regulations and laws was reported as another point of concern, due to the difficulty of making some information in laws or regulation (usually about exceptions or applicability) conform to the object/attribute data model. Further, sometimes the original text leaves room for interpretation. Regulations are often written to fit specific circumstances which were not considered general enough to warrant capture in the SNPWG model. Apart from this issue, the S-100 framework currently lacks convenient modeling elements for expressing procedural and rule-based knowledge. It is theoretically possible to capture such information in an object/attribute model, but the non-intuitive structures increase the difficulty of information mapping.

The mapped and cleaned data was converted into data sets conforming to the encoding specification developed for DMRG. The results were reviewed by the hydrographic office partners. The results can be viewed in an XML editor tool as well as a popular off-the-shelf free GML viewer.

\section{INTERFACE FUNCTIONALITY}

The characteristic feature of mariners' routeing guides is the balance between graphical, chart-like and text-heavy presentations. In this, they differ from both nautical charts (heavily graphical) and nautical publications (heavily textual). The DMRG attempts to balance geographic and textual information and provides both geographic browsing and textual presentations of information.

\section{Geographic Browsing}

The user can select feature classes (layers) for display and highlighting on the graphic display. Feature classes or layers correspond to vector objects as encoded in the spatial data available to the system, such as VTS service areas, major navigational aids, pilot services, etc. Activating a layer or feature in the Layers and Features panel displays and highlights the relevant feature(s). Clicking a feature in the graphic window brings up a popup with information about the feature. Figure 1 shows this functionality in action. 


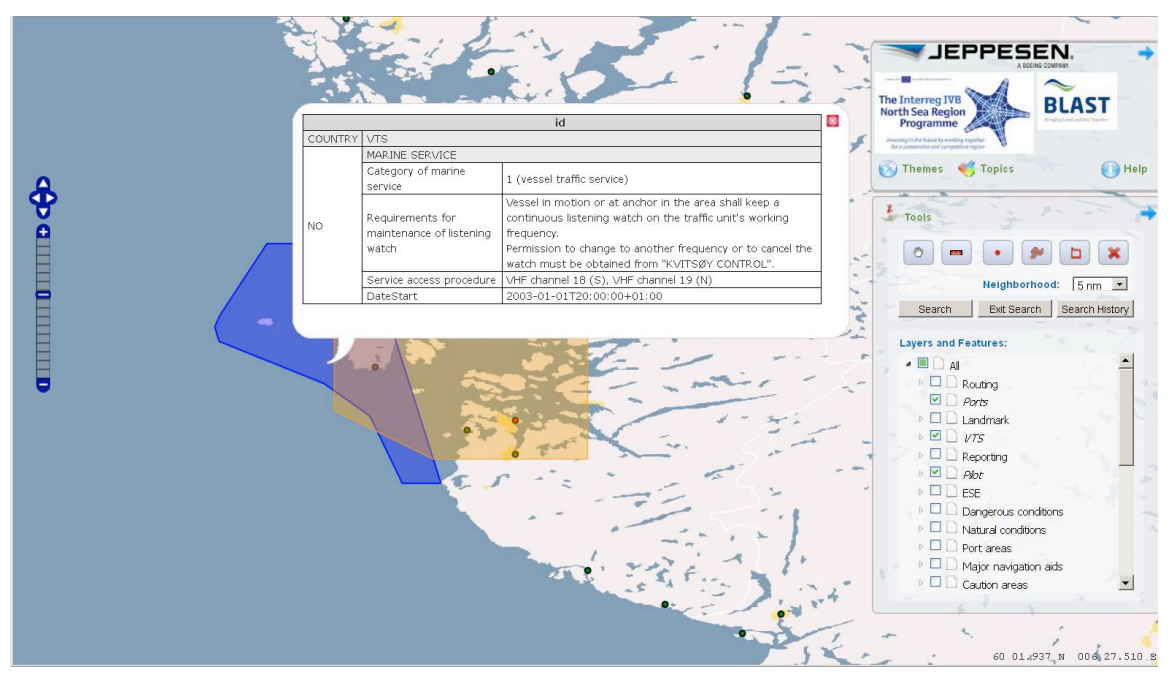

Figure 1: Users can browse for information on a single geographic feature using the graphical interface. Shown is the VTS area in the vicinity of Stavanger (blue highlight). The other feature represents the pilot service area for the region.

\section{Structured Presentations of Text}

The system provides a menu-based interface which allows the user to obtain results about a single feature class, a group of feature classes (topics), or a broad subject (themes menu). As shown in Figure 2, clicking a theme or topic item displays information in text or mixed text/graphic form, depending on what is available.

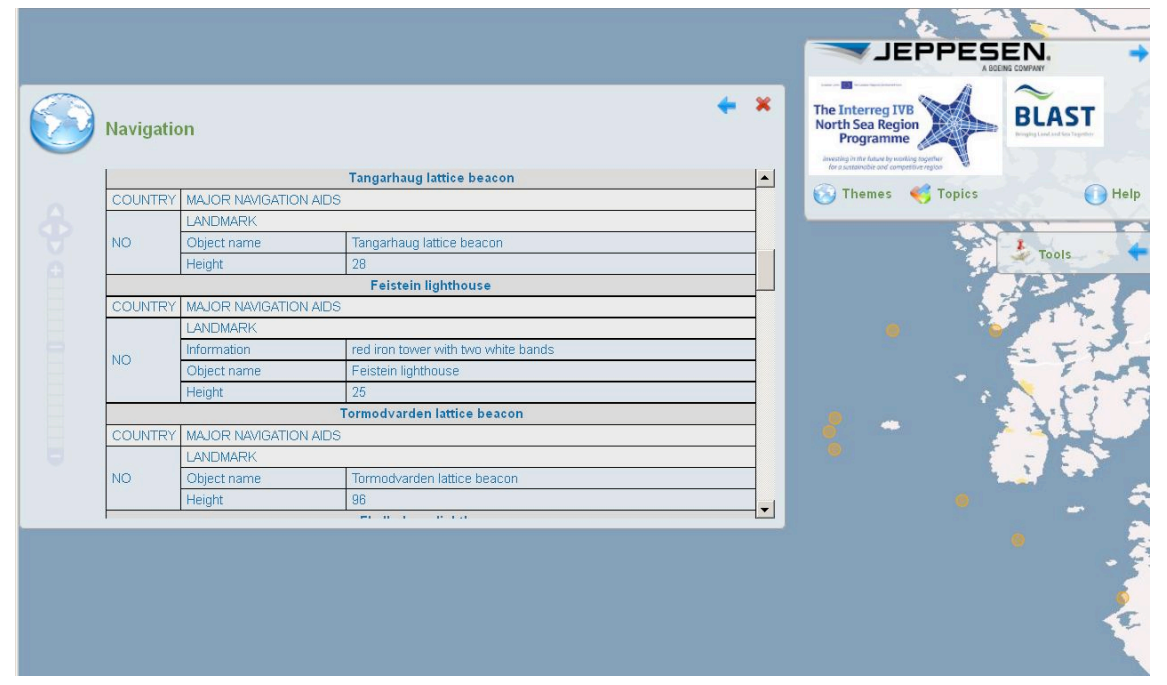

Figure 2: Organised text-based presentations about selected topics or broader subjects are available. The text box shows information about important navigation aids in the vicinity of Stavanger. The graphic display shows their locations.

\section{Support for Voyage Planning}

One of the most important activities of navigation officers on commercial vessels is voyage planning. The DMRG supports this function by providing geographic queries. A route query function allows the user to obtain all information intersecting, or in the neighbourhood of a route specified by the user 
(Figure 3). Area, region, or point-based queries can be used to find information pertaining to a specific area, region, or location.

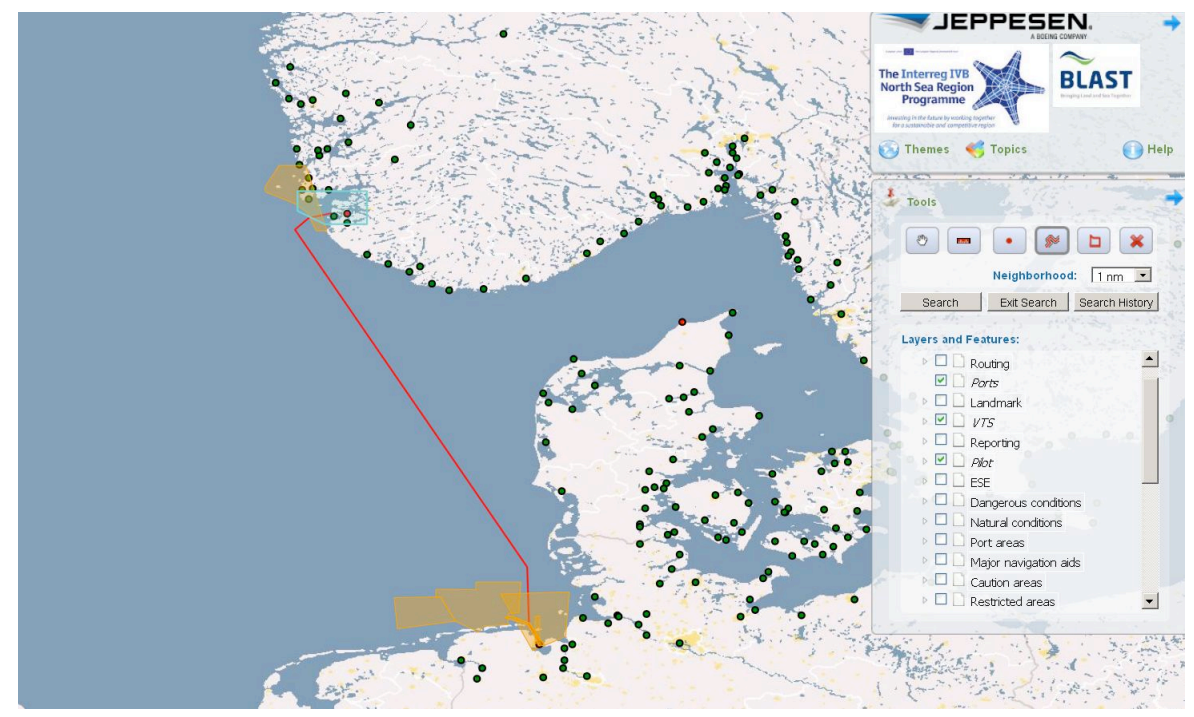

Figure 3: Users can retrieve information pertaining to specified locations, routes, areas, or regions. The figure shows an example route between Wilhelmshaven and Risavika, specified by the user. Executing searches displays information for locations within a user-configurable cross-track distance.

\section{OTHER ROUTEING GUIDES}

The Admiralty routeing guide for the English Channel and Southern North Sea and the BSH routeing guide for the Baltic are a large format paper charts containing a mixture of text, diagrams, and specialised chart images. The contents include general information and guidelines for using the routeing guide, overviews of routeing schemes, an overview of international and local regulations and extracts from International Maritime Organisation (IMO) codes and the MARPOL conventions, considerations for tankers, and ships carrying hazardous cargo, outlines of reporting systems and requirements, radio services, information about VTS and pilot services.

There is also a Digital Mariners' Routeing Guide for the Baltic Sea, produced by collaborative efforts Denmark, Estonia, Finland, Germany, Latvia, Lithuania, Poland, Russia, and Sweden. The online version can be viewed at http://www.helcom.dk/map/index.htm. It provides information similar to that found in the other routeing guides described. The web-based version offers additional functionality of allowing users to select a view of routeing and planning information by subtopic, or filter the content by Country or topic. Drill-down access to topics such as Pilotage for a country triggers presentation of detailed text, chart images and diagrams in the form of PDF documents.

"DigiPilot", produced by the Hydrographer of the Royal Netherlands Navy as an official nautical publication, is interactive software with content from Dutch Sailing Directions, tidal information, the Netherlands Mariners Routing Guide for the Southern North Sea and Deep Draught Planning Guide. It provides interactive query functionality and multiple thematic layers.

\section{DISCUSSION}

As part of the BLAST (Bringing Land and Sea Together) project, Jeppesen collaborated with the hydrographic offices of the Federal Republic of Germany, Norway, and Denmark on a sequence of activities intended to advance the cause of harmonized and efficient information collection and demonstrate its delivery using the S-100 framework. The DMRG is the final phase and builds on activities in earlier phases on collecting and harmonising information. 
The DMRG project demonstrates that standardized information models can be used for very different types of information, specifically text-based as well as vector data. It demonstrates the application of harmonised information modeling from different European nations, by making an information model and datasets derived from different countries, structured in different ways, and containing very different types of data (vector data and text-based information). It also demonstrates the integrated use of marine information, specifically vector data used in ENCs with text-based information form nautical publications, and its presentation to end-users in an integrated fashion - chart objects (ENC data) are presented seamlessly with text-based information from nautical publications.

Our experiences during the conversion of data to the common data model suggest that significant effort may be needed to map non-ENC data to S-100, and also to convert existing data. The mapping and conversion process helps discover gaps, ambiguities, and discrepancies in existing data, which results in improvements to the quality of the source data as well as the result. On the other hand, not everything in text sources can be mapped to an object-attribute model like S-100, due to the complexities of human language.

Finally, it is clear that a Digital Mariners' Routeing Guide can support more content and more varied content than the paper version because the digital medium makes it possible to dynamically maintain an organised, context-driven presentation of relevant information, and permits the dynamic selection of information for the end-user.

\section{ACKNOWLEDGMENTS}

The work described here was part of the Bringing Land and Sea Together (BLAST) project. Jeppesen's participation is funded in part by the INTERREG IVB North Sea Region Programme and in part by Jeppesen. We gratefully acknowledge the participation of personnel from Bundesamt für Seeschifffahrt und Hydrographie (BSH - Federal Republic of Germany), Norwegian Hydrographic Service/Statens Kartverk Sjø (NHS - Norway), and Kort \& Matrikelstyrelsen (KMS - Denmark), whose participation was funded in part by the INTERREG IVB programme and in part by their respective agencies.

\section{CONCLUSION}

A digital Mariners' Routeing Guide includes information about international and local regulations and practices, as well as a combination of chart and nautical publications information on a trans-national basis. It therefore provides a useful reference point and test bed for exploring the standards-based preparation and distribution of information, and the integration of geographic data with other forms of information. The work described here demonstrates that new standards for marine information can be successfully employed in integrated presentations of spatial and non-spatial information.

\section{REFERENCES}

International Hydrographic Organisation. 2010a. "Standardization of Mariners' Routeing Guides". Edition 2.0. Publication S-49, International Hydrographic Bureau, Monaco.

International Hydrographic Organisation. 2010b. "S-100 - Universal Hydrographic Data Model". Edition 1.0.0. Publication S-100, International Hydrographic Bureau, Monaco.

\section{BIOGRAPHIES}

Raphael M MALYANKAR is a consulltant for Jeppesen working on marine standards and information models for marine data. His professional interests include information modeling and knowledge representation for geospatial information. His academic trainng is in computer science. His highest degree is a Ph.D. in computer science from Arizona State University. 
CONTACT DETAILS (of corresponding author only)

Raphael M MALYANKAR

c/o Cathrine Fierberg

Jeppesen

55 Inverness Drive East,

Englewood, CO 80112

USA

Tel.: +1 4804913997

Email: Raphael.Malyankar@jeppesen.com

Web site: http://www.jeppesen.com 